\title{
Multi-energy Network Model of Virtual Energy Router
}

\author{
Yang Chen ${ }^{1}$, Luqing Zhang ${ }^{2}$, Aikang Chen ${ }^{2}$, Yanchi Zhang ${ }^{1}$ and Da Xie ${ }^{2, *}$ \\ ${ }^{1}$ School of Electrical Engineering, Shanghai Dianji University, 201306 Shanghai, China \\ ${ }^{2}$ School of Electronic Information and Electrical Engineering, Shanghai Jiaotong University, 200240 Shanghai, China
}

\begin{abstract}
Energy router is the main equipment of energy Internet to interact through energy and information. This paper proposes the routing algorithm of the virtual energy router composed of multiple energy routers and constructs the multi-energy coupling correlation model, and combines internal routing algorithm of the virtual energy router with multi-energy correlation model to plan the capacity of energy routers in the regional energy network composed of multiple parks. The simulation shows that the planning method based on the routing algorithm improves the energy, environment and economic benefits of the regional energy wide area network.
\end{abstract}

\section{Introduction}

Energy Internet is described as an energy utilization system characterized by the in-depth integration of new energy technology and information technology. It is a distributed and open sharing network based on renewable energy [1,2]. Energy router is the main equipment of energy Internet to interact through energy and information. In the [3] literature, the concept of virtual energy router is proposed to centralize the management and operation of energy router. Virtual energy routers realize aggregation and multi-energy coordination optimization of multiple decentralized energy routers through information communication and intelligent computing technology. In previous energy systems, plan and design are carried out independently, which ignores the correlation between multiple energy systems[4]. Under the background of the rapid development of energy Internet in related research, the research object of the program also becomes the energy Internet with strong coupling characteristics, so as to improve the comprehensive energy utilization of the system[5]. In order to show the synergistic optimization and complementarity of multiple energy interconnecttions and conversions in the planning, it is necessary to conduct modeling and analysis of system of the energy interconnections formed by coupling of multiple energy subsystems.

\section{Multi-energy complementary energy router}

\subsection{Multi-energy complementary energy router}

With the development and promotion of integrated energy system, the integrated energy system under the energy Internet architecture will become a huge distributed group.

Therefore, the multi-energy complementary energy router is proposed. In essence, the single electric-electric conversion of the original energy router is extended to realize the conversion of multiple energy. The specific structure is shown in figure 1.

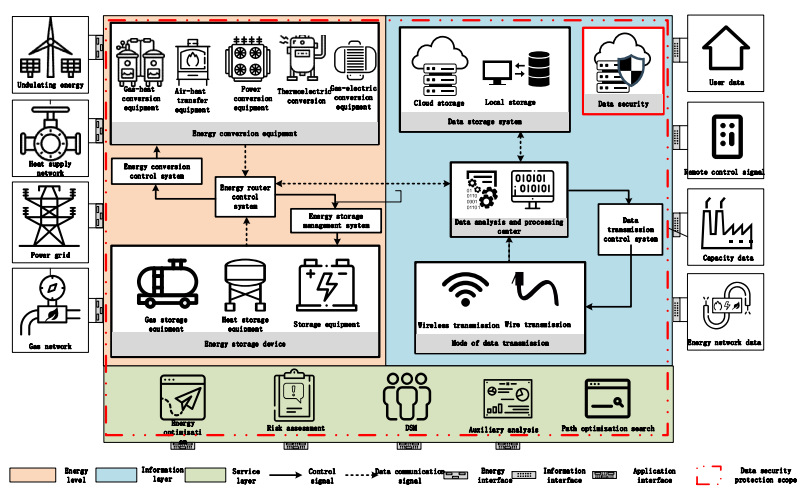

Fig.1. Structure of multi-energy complementation router

At present, its own interests, which inevitably leads to the unreasonable configuration and operation of energy components, resulting in the sub-optimal efficiency of the energy Internet in terms of energy, economy and environment optimal, and may even affect the security of the system are often only considered in the planning or operation of the park-level energy local area network. VERs can solve the above problem very well.

\subsection{Routing algorithm}

Routing algorithm $[6,7]$ is an algorithm that improves protocol function and minimizes routing overhead. Routers use routing algorithms to find the best link to a destination

\footnotetext{
* Corresponding author: xieda@sjtu.edu.cn
} 


\subsection{Routing algorithm of VERs}

The internal algorithm of VERs is defined as : $\left(\mathrm{ER}_{j}, \mathrm{ER}_{k}\right)$ represents the connection between the energy router's $\mathrm{ER}_{j}$ and $\mathrm{ER}_{k} . \mathrm{ER}_{m}$ and $\mathrm{ER}_{n}$ represent all source energy routers and terminal energy routers, respectively. $\Pi\left(\mathrm{ER}_{m}, \mathrm{ER}_{n}\right)$ represents the set of all paths from $\mathrm{ER}_{m}$ to $\mathrm{ER}_{n} \quad, \pi\left(\mathrm{ER}_{m}, \mathrm{ER}_{n}\right) \in \prod\left(\mathrm{ER}_{m}, \mathrm{ER}_{n}\right)$ represents one path from $\mathrm{ER}_{m}$ to $\mathrm{ER}_{n}$. Hence, the energy cost of the entire regional energy Internet $\mathrm{C}_{\text {total }}$ is defined as (1):

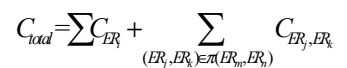

In the formula, $\mathrm{C}_{E R i}$ represents the $\mathrm{i}$-th energy cost inside the power router.

\section{Planning and design of area energy wan}

\subsection{Basic model}

\subsubsection{Expanded model of Energy hub}

The concept of Energy Hub[8]（Energy Hub, EH） is adopted to build the model to analyze the transformation, storage and distribution of various kinds of energy in the virtual energy router better. The literature[9] connects the input, transformation and output of various energy sources together, energy interaction and coupling can be more directly reflected, which is defined as (2):

$$
O=C I
$$

I, C, O represent input, transformation, output matrix of Energy Hub, respectively .Combined with all the energy of supply side, conversion side and load side, the following expanded model of Energy Hub can be obtained,whose specific fomular (3) is as follow :

$$
O=O T(C+C T)\left(I^{\text {basic }}+I^{P 2 G}+I^{W T}+\cdots\right)+S
$$

In the formula, $\mathrm{O}, \mathrm{OT}, \mathrm{S}$ represent output matrix, transmission loss matrix from conversion side to load side, energy storage matrix , respectively ; $\mathrm{C}$ means conversion matrix, CT means transmission loss matrix from supply side to conversion side; $\mathrm{I}^{\text {basic }}, \mathrm{I}^{P 2 G}$ and $\mathrm{I}^{W I}$ represent basic equipments, $\mathrm{P} 2 \mathrm{G}$ and matrix of waste incineration power generation in supply side .

\subsubsection{Flow models of Electricity, Heat, Gas}

Limited by space, this article does not elaborate specific flow models of Electricity, Heat, Gas.

\subsection{Correlation model}

The correlation model is the correlation equation among the location and capacity of electric, thermal and gas energy components of multiple ER in VERs, which is as follow(4):

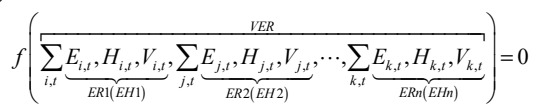

$\mathrm{E}_{i, t}, \mathrm{H}_{i, t}, \mathrm{~V}_{i, t}$ represent the state of electricity, heat and gas energy in the $\mathrm{i}$-th component of ER1 at time $\mathrm{t}$. Taking P2G for example, its energy state $\mathrm{E}$ is negative value, $\mathrm{H}$ is $0, \mathrm{~V}$ is positive value, indicating that it consumes electricity to produce gas. The correlation model can reflect the energy states of all energy elements in VERs, and joint planning of all the energy components in the VERs is implemented. At the same time, it reflects a relationship of mutual restraint and influence when energy components of VERs are at constant capacity.

\section{Planning model of regional energy wan based on routing algorithm}

\subsection{Planning guidelines}

Planning guidelines is that firstly the parameters of energy components are taken as decision variables, and the target is the annual cost of the park level energy LAN, which includes all the costs after the transformation of energy, economy and environment, and the operating costs are also included. The operating cost is calculated by the collaborative scheduling optimization of each energy element, which is limited by the parameters of the energy element.Therefore, these two steps will constrain each other, and a more realistic planning scheme will be obtained after repeated iterations.

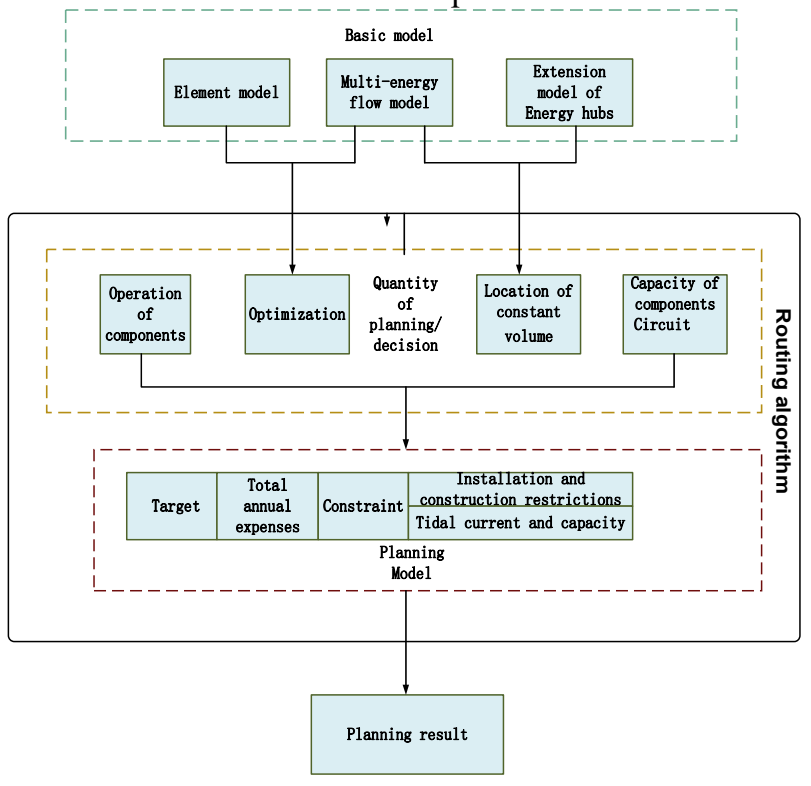

Fig.2. Planning guideline

The path planning problem of the electric-thermal convergence network among energy routers is divided into 9 categories, namely, new construction, unchanged and expanded capacity of electric, thermal and gas networks. Two groups of $0-1$ variables are used to represent whether to build and expand capacity respectively. The overall process of planning thinking is shown in figure 2.

\subsection{Planning model based on routing algorithm}


Considering the planning model of internal routing algorithm, the annual total cost of regional energy wan is taken as the target, the parameter of energy element is taken as the decision-making quantity, and the energy element scheduling quantity is taken as the decisionmaking quantity.

\subsubsection{Objective function}

The planning goal is to have a minimum annual cost $\mathrm{F}$,which includes investment costs $\mathrm{C}_{i n v}$ for energy components, operating cost $\mathrm{C}_{\text {ope }}$, subsidies $\mathrm{C}_{\text {allo }}$ of clean energy and environmental maintenance cost $\mathrm{C}_{\text {save }}$. The operating cost is the target of the lower model. Specific formula is as follow (5):j

$$
F=C_{i n v}+C_{\text {ope }}+C_{e p}-C_{\text {allo }}-C_{\text {save }}
$$

\subsubsection{Constraint condition}

There are three kinds of constraints, containing the limits on the installable capacity of energy components, the mutual restriction formed by relationship of the energy flow within the park and logical relation constraint of variables. Specific formula is as follow (6):

$$
\left\{\begin{array}{l}
V_{i, \text { min }} \leq V_{i} \leq V_{i, \text { max }} \\
G_{i, j}\left(V_{i, j}\right) \leq 0 \\
L_{i, j}(x, y) \leq 0
\end{array}\right.
$$

$\mathrm{V}_{i, \max }, \mathrm{V}_{i, \min }$ represent upper and lower limits of installable capacity, $\mathrm{G}_{i, j}\left(\mathrm{~V}_{i, j}\right)$ means constraints arising from the energy flow of capacity, $\mathrm{L}_{i, j}(\mathrm{x}, \mathrm{y})$ is logical relation constraint of variable. In addition, the constraints include constraints of power flow and capacity.

\section{Analysis of example}

Taking the three park-level energy local networks in the region shown in figure 3 as examples to plan regional wide area network this section.

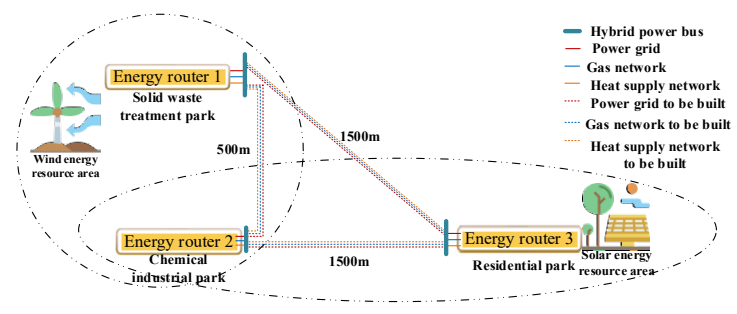

Fig.3. Regional energy wide area network

Park 1 is a solid waste treatment park. The only external resources needed in the park are garbage, and it can produce biogas, natural gas and other energy. Park 2 is a chemical industry park. The chemical plant needs natural gas as raw material for production, so its internal load is not only the conventional electrical and thermal load, but also the gas load. The daily load of chemical industry park fluctuates little because of the uninterrupted demand of production. Park 3 is a residential park with residents' daily behavior characteristics. Therefore, its hot and cold loads are obviously "concave", while the electrical load only increases significantly during off-duty hours. The solar and wind energy sources provide electricity together. The parameters of the energy components involved in the plan are shown in table 1 .

\begin{tabular}{|c|c|c|c|}
\hline $\begin{array}{c}\text { Energy } \\
\text { components }\end{array}$ & $\begin{array}{c}\text { Unit capacity } \\
\text { investment } \\
\text { expense }\end{array}$ & $\begin{array}{l}\text { Operational } \\
\text { costs }\end{array}$ & $\begin{array}{l}\text { Planable } \\
\text { position }\end{array}$ \\
\hline $\begin{array}{l}\text { Refuse landfill } \\
\text { waste }\end{array}$ & 6.1429 & 0.84 & 1 \\
\hline $\begin{array}{l}\text { incineration } \\
\text { power plant }\end{array}$ & 3557.1 & 13.5 & 1 \\
\hline $\begin{array}{l}\text { Leachate } \\
\text { treatment plant }\end{array}$ & 18386 & 5.93 & 1 \\
\hline $\begin{array}{l}\text { Biogas power } \\
\text { plant }\end{array}$ & 1700 & 0.0074 & 1 \\
\hline $\begin{array}{c}\text { Gas } \\
\text { compression } \\
\text { purification } \\
\text { station }\end{array}$ & 65 & 0.0525 & 1 \\
\hline $\mathrm{P} 2 \mathrm{G}$ & 800 & 0.042 & 1,2 \\
\hline Wind motor & 12500 & 0.01 & 1,2 \\
\hline PV & 8500 & 0.01 & 2,3 \\
\hline Gas turbine & 15000 & 0.025 & 2 \\
\hline Gas boiler & 340 & 0.02 & 2 \\
\hline Heat pump & 3000 & 0.0097 & 2,3 \\
\hline $\begin{array}{l}\text { Electrical } \\
\text { refrigeration }\end{array}$ & 1100 & 0.01 & 2,3 \\
\hline $\begin{array}{l}\text { Absorption } \\
\text { refrigeration }\end{array}$ & 1100 & 0.008 & 2,3 \\
\hline Power storage & 142.86 & 0.00027 & $1,2,3$ \\
\hline $\begin{array}{c}\text { Heat } \\
\text { accumulation }\end{array}$ & 321.6 & 0.0315 & $1,2,3$ \\
\hline Gas storage & 5 & 0.00024 & $1,2,3$ \\
\hline
\end{tabular}

Table 1. Parameters of energy unit

Combined with genetic algorithm and constraint linearization, the planning results are shown in figure 4 and table 2 .

As the requirements of park 2 and 3 depend on the supply of park 1 in electricity and heat load, biogas power plants are not superior in terms of environment and energy efficiency, but they still plan less capacity to meet the load demand. Park 1 is an energy supply park, so no energy storage equipment is planned in it. In park 2 , the electric load can be supported by park 1 , but because of the stimulation of sales profit of electric energy, the supply of wind and solar power is not 0 .

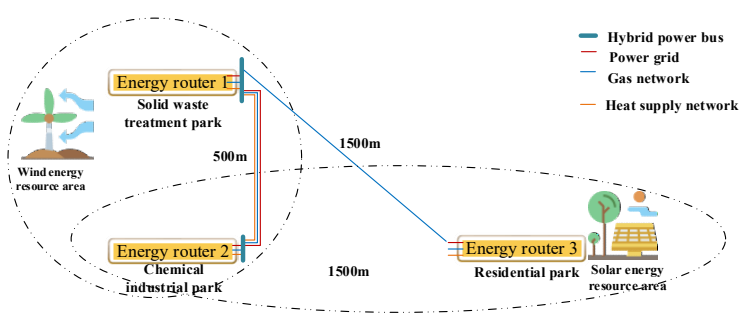

Fig.4. Result of the planning

The energy source of park 3 is the power transmission and internal photovoltaic power generation planning of park 1. Because park 1 has sufficient electric energy, park 3 has small power load, and photovoltaic investment cost is not low, so park 3 does not plan photovoltaic. Energy storage in park 2 and park 3 is a certain amount of energy storage planning. In addition, there is no common network between the cooling load 
in each park, so the cooling load of park 2 and 3 is produced by internal equipments of electrical refrigeration and absorption refrigeration.

If the internal routing algorithm of the virtual energy router is not taken into account- independent operation planning of each park, the comparison of energy, economy and environment with the planning results in this chapter is shown in table 3: investment, operation and maintenance costs, energy purchase costs and carbon emissions increase, and energy utilization rate decreases.

Table 2. Capacity of energy units

\begin{tabular}{|c|c|c|c|}
\hline Energy components & Park 1 capacity & Park 2 capacity & Park 3 capacity \\
\hline Refuse landfill & $1264 \mathrm{t} / \mathrm{d}$ & / & / \\
\hline waste incineration power plant & $4742 \mathrm{t} / \mathrm{d}$ & I & l \\
\hline Leachate treatment plant & $2050 \mathrm{~m}^{3} / \mathrm{d}$ & / & / \\
\hline Biogas power plant & $4342 \mathrm{~kW}$ & / & / \\
\hline Gas compression purification station & $75024 \mathrm{~m}^{3} / \mathrm{d}$ & / & / \\
\hline$P 2 G$ & / & $2000 \mathrm{kw}$ & / \\
\hline Wind motor & / & $500 \mathrm{kw}$ & $0 \mathrm{kw}$ \\
\hline PV & $677 \mathrm{kw}$ & $320 \mathrm{kw}$ & / \\
\hline Gas turbine & / & $0 \mathrm{kw}$ & / \\
\hline Gas boiler & / & $0 \mathrm{kw}$ & / \\
\hline Heat pump & / & $250 \mathrm{kw}$ & $323 \mathrm{kw}$ \\
\hline Electrical refrigeration & / & $50 \mathrm{kw}$ & $585 \mathrm{kw}$ \\
\hline Absorption refrigeration & / & $0 \mathrm{kw}$ & $0 \mathrm{kw}$ \\
\hline Power storage & $0 \mathrm{kWh}$ & $487 \mathrm{kwh}$ & $0 \mathrm{kWh}$ \\
\hline Heat accumulation & $0 \mathrm{kWh}$ & $5820 \mathrm{kwh}$ & $2540 \mathrm{kWh}$ \\
\hline Gas storage & $0 \mathrm{~m}^{3}$ & $320 \mathrm{~m}^{3}$ & $0 \mathrm{~m}^{3}$ \\
\hline
\end{tabular}

Table 3. Comparison of area planning and independent planning

\begin{tabular}{ccccccc}
\hline & \multicolumn{3}{c}{ Cost(ten thousand yuan) } & \multicolumn{3}{c}{ Rate of energy utilization (\%) } \\
& Investment+OPS & Power Purchase & Power & Heat & Gas & Carbon emission (t/d) \\
\hline Regional planning & 12386 & 0 & 1 & 1 & 0.91 & 5774.2 \\
Independent planning & 13113 & 352.56 & 0.97 & 1 & 0.89 & 12342.3 \\
\hline
\end{tabular}

\section{Conlusion}

This paper presents the planning method of multi-energy network model based on the routing algorithm of virtual energy router, which reflects the planning benefit of virtual energy router. Results of simulation show that the virtual energy router and its routing algorithm are effective.

\section{Acknowledgement}

The research in this paper was supported by Research on Energy Systems of Smart Park. Research and Demonstration on Key Technologies of Multifunctional Energy Router of Shanghai Science and Technology Commission (18DZ1203700).

\section{References}

1. RIFKIN J. J. International Study Reference, 3. $7(2008)$

2. L. Cheng, T. Yu, H. Jiang, S. Shi, Z. Tan and Z. J. IEEE Access. 7. 21( 2019)

3. S. Shan, N. K. Nakul and L. IEEE PES Innovative Smart Grid Technologies Conference Europe (ISGT-Europe), Sarajevo, 2018

4. Xiaodan $\mathrm{Yu}, \mathrm{Xiandong} \mathrm{Xu}$, Shuoyi Chen, et al. J. Transactions of China Electrotechnical Society. 31. 12 (2016)
5. Yang Li, Ming Wu, Haiming Zhou, et al. J. Power System Technology, 39. 8(2015)

6. Qi Bing, Liu Lin, Li Bin, et al. J. Proceedings of CSEE. 2019

7. H. Guo, F. Wang, L. Li, J. Zhang and J. Luo. IEEE Transactions on Industrial Informatics

8. ZHANG $\mathrm{X}$, SHAHIDEHPOUR $\mathrm{M}$, ALABDULWAHAB A. IEEE Transactions on Industrial Informatics

9. Wei Ni, Lin Lu, Yue Xiang et al. J. Power System Technology, 42. 8(2018) 